\title{
A RESPONSABILIZAÇÃO DO FORNECEDOR PELO DESVIO PRODUTIVO DO CONSUMIDOR E O DANO TEMPORAL
}

\section{THE RESPONSIBILIZATION OF THE SUPPLIER FOR CONSUMER PRODUCTIVE DEVIATION AND TEMPORARY DAMAGE}

\author{
Mariana Dionísio de Andrade ${ }^{1}$ \\ Eduardo Régis Girão de Castro Pinto ${ }^{2}$ \\ Larissa Magalhães Aragão ${ }^{3}$
}

\section{RESUMO}

O presente estudo tem como objetivo responder ao seguinte problema de pesquisa: é possível responsabilizar o fornecedor pelo desvio produtivo do consumidor, considerando o prejuízo do tempo desperdiçado na busca pela solução de problemas não ocasionados por este? Para abordar o tema de maneira mais ampla, foi necessária a compreensão sobre preceitos consumeristas e suas características, o conceito de novos danos, a tutela ao tempo, bem como a banalização da responsabilidade civil ao dano temporal. A metodologia utilizada é classificada como bibliográfica, pura, qualitativa e descritiva. O estudo é embasado em obras de Nelson Rosenvald, Claudia Lima Marques, Bruno Miragem e Marcos Dessaune, dentre outros. É possível concluir que o desvio produtivo do consumidor tem sido objeto de discussões, sobretudo com aumento de demandas em que se admite a responsabilidade civil do fornecedor pela perda do tempo útil.

Palavras-chave: Responsabilidade civil. Tutela do tempo. Desvio produtivo do consumidor.

\footnotetext{
${ }^{1}$ Doutora em Ciência Política pela Universidade Federal de Pernambuco. Mestre em Direito Constitucional pela Universidade de Fortaleza - UNIFOR. Especialista em Direito Processual Civil pela UNIFOR. Professora do Curso de Pós-Graduação lato sensu em Direito e Processo Constitucionais e da disciplina Teoria Geral do Processo Civil no Curso de Graduação em Direito na Universidade de Fortaleza. Formação em Leadership and Conflict Management pela Stanford University. Formação em Métodos Quantitativos pela UERJ. Pesquisadora do Grupo Epistemologia e Método na Ciência Política Comparada (Cnpq/UFPE). Coordenadora do Projeto Processo Civil e Proteção da Pessoa nas Relações Privadas (Cnpq/ UNIFOR). Advogada. Universidade de Fortaleza - UNIFOR - Brasil. ORCID: http://orcid.org/0000-0001-8698-9371 Lattes: http://lattes.cnpq.br/2375238086112583 E-mail: mariana.dionisio@gmail.com

2 Doutorando em Direito Constitucional e Mestre em Direito Constitucional pela Universidade de Fortaleza. Professor do Curso de Pós-Graduação lato sensu em Processo Civil da Escola Superior da Magistratura do Estado do Ceará. Professor dos Cursos de Pós-Graduação lato sensu em Direito Empresarial, Direito dos Contratos e Responsabilidade Civil e Direito do Consumidor, e do Curso de Graduação em Direito na UNIFOR. Coordenador do Projeto de Pesquisa Processo Civil e Proteção da Pessoa nas Relações Privadas (Cnpq/UNIFOR). Assessor jurídico da 2a Câmara de Direito Privado do Tribunal de Justiça do Estado do Ceará. Universidade de Fortaleza UNIFOR - $\quad$ Brasil. ORCID: https://orcid.org/0000-0001-6949-4940 Lattes: http://lattes.cnpq.br/8322517576164876E-mail: eduardogirao@gmail.com

${ }^{3}$ Especialista em Responsabilidade Civil e Direito do Consumidor pela Universidade de Fortaleza. Advogada. Universidade de Fortaleza - UNIFOR - Brasil. ORCID: https://orcid.org/0000-0003-1293-9675 Lattes: http://lattes.cnpq.br/3851421569177335 E-mail: aragaomlarissa@gmail.com
} 


\begin{abstract}
This study aims to respond to the following research problem: is it possible to blame the supplier for the productive deviation of the consumer, considering the time wasted in the search for the solution of problems not caused by this? To address the issue in a broader way, it was necessary to understand consumer precepts and their characteristics, the concept of new damages, the protection of time, as well as the banalization of civil liability to temporal damage. The methodology used is classified as bibliographical, pure, qualitative and descriptive. The study is based on literature approaches by Nelson Rosenvald, Claudia Lima Marques, Bruno Miragem and Marcos Dessaune, among others. It is possible to conclude that the productive deviation of the consumer has been the subject of discussions, especially with increasing demands in which the civil liability of the supplier is admitted by the loss of useful time.
\end{abstract}

Keywords: Civil liability. Time protection. Productive deviation of the consumer.

\title{
INTRODUÇÃOO
}

Com o crescimento do consumo, principalmente após a entrada em vigor do Código de Defesa do Consumidor em 1990, passou-se a observar a relação entre consumidores e fornecedores como uma dinâmica repleta de direitos e deveres. Dentre os fenômenos existentes nessa relação, visualiza-se o denominado Desvio Produtivo do Consumidor.

Frequentemente, indivíduos se veem obrigados a alterar rotinas pessoais e profissionais para solucionar problemas de consumo ocasionados por fornecedores. É exatamente sobre a relevância jurídica do tempo despendido que este artigo se destina. A questão envolve os direitos do consumidor, inseridos em um microssistema de proteção em decorrência da vulnerabilidade existente na relação de consumo, como forma de equilibrar um panorama jurídico, vedando práticas abusivas e responsabilizando aqueles fornecedores que não atendem as prerrogativas legalmente estabelecidas.

A realidade comporta eventos de descaso ao consumidor, por vezes compelido a suportar serviços de qualidade questionável, fornecimento de produtos com vícios, inadequação dos produtos, obsolescência programada, inconformidades materiais; o que deveria ocorrer de forma pontual e não contumaz, pois um dos pilares do mercado de consumo deveria ser, justamente, a interligação ótima entre fornecedor e consumidor.

O consumidor, na tentativa de resolver o problema, não perde apenas tempo, mas também adia e/ou suprime atividades anteriormente previstas, deixa de cumprir com eventuais programações pessoais ou compromissos de ordem profissional, ocasionando um efetivo prejuízo de natureza existencial em razão do tempo ter caráter limitado. 
Dessa forma, justifica-se a presente pesquisa pela necessidade de compreender a tutela ao tempo, na perspectiva consumerista de abuso de direito, possivelmente sendo considerado um novo dano, considerando as controvérsias doutrinarias e jurisprudenciais a respeito do tema.

Tem-se como objetivo geral a análise da perda do tempo livre do consumidor como dano indenizável. Como objetivos específicos, visa-se compreender os direitos do consumidor e suas características; esclarecer o abuso de direito e a tutela ao tempo; e identificar a evolução da teoria do desvio produtivo perante o Poder Judiciário.

Quanto à metodologia, o artigo possui abordagem bibliográfica, utilizando as obras de Nelson Rosenvald, Claudia Lima Marques, Bruno Miragem e Marcos Dessaune, além de outros livros e periódicos que analisam os temas de direitos do consumidor, responsabilidade civil, novos danos, principalmente no que diz respeito à tutela ao tempo.

Em relação à aplicação dos resultados, a pesquisa classifica-se como pura e qualitativa, tendo em vista sua finalidade, inicialmente, de expansão de conhecimentos, e descritiva, pois explicita a situação no momento em que ocorre a investigação, classificação e interpretação dos fatos. Quanto à abordagem, a pesquisa enfatiza a compreensão e a interpretação do tema, atribuindo significado às informações coletadas.

$\mathrm{O}$ artigo se divide em dois tópicos. No primeiro tópico, abordam-se as relações entre fornecedores e consumidores, tratando da evolução dos preceitos consumeristas, as principais características destes direitos, lesões que podem ensejar responsabilidade civil, bem como o reconhecimento dos conceituados novos danos. O segundo tópico é dedicado à análise do desvio produtivo do consumidor no tempo. Analisa-se o abuso de direito, averiguando o tempo como bem jurídico tutelado pelo ordenamento jurídico para, assim, enfrentar o reconhecimento do dano temporal como uma nova espécie.

O artigo é relevante em termos teóricos porque oferece uma importante contribuição para a literatura sobre o assunto, possibilitando uma perspectiva mais específica e atualizada acerca das relações consumeristas e da evolução dos institutos jurídicos que tutelam a proteção individual. Ainda, possui relevância prática porque aborda uma temática de imperiosa preocupação; a identificação de possibilidades de defesa do consumidor com base na responsabilização pelo desvio produtivo do cidadão, sobretudo pelo trabalho desenvolvido pelos profissionais da área jurídica.

\section{OS DIREITOS DO CONSUMIDOR}


A fim de adentrar no estudo sobre direitos do consumidor, inicialmente impõe-se a compreensão das relações entre fornecedores e consumidores. Em meados do século XIX ocorreu o fenômeno da contratação em massa, período em que o expansionismo industrial se modificou para o mercantil, acarretando elevado número de relações contratuais. (SCHMITT, 2010). A massificação na produção deixou o consumidor em desvantagem, pois "à medida que o fornecedor se fortaleceu técnica e economicamente, o consumidor teve o seu poder de escolha enfraquecido, praticamente eliminado.” (CAVALIERI FILHO, 2014, p. 98).

Em virtude da massificação, muitos consumidores passaram a manter uma postura passiva em relação aos contratos de adesão, sem oportunidade de participar da elaboração dos termos contratuais, restando aceitar as cláusulas impostas pelos fornecedores, caso contrário não teriam acesso ao produto ou serviço que careciam. O consumo é parte inerente da vida cotidiana, portanto, percebe-se que o consumidor, como parte vulnerável nesta relação, acaba por celebrar contratos não condizentes com a bilateralidade que deveria ser própria, caracterizando um acentuado desequilíbrio na relação.

É preciso mencionar que os fornecedores são a parte mais forte na relação, sobretudo no que concerne às informações quanto à produção e comercialização dos bens, mapeando o poder de compra e, ainda, atuando concretamente no planejamento de produção de seus pares. (AZEVEDO, 2009). Assim, o que deveria ser benefício ao consumidor, no que diz respeito à redução de preço e ampliação do serviço, já que os contratos de adesão facilitaram o comércio, em verdade, tornou-se uma grande problemática em razão da excessiva proporção que os impasses provocaram no mercado.

Fornecedores não deveriam abusar da cadeia de comércio, já que são justamente os clientes que contribuem para o pleno funcionamento do mercado, na medida em que "quem garante todos os empregos não são os empresários, os sindicalistas ou os governantes, mas sim os consumidores.” (HICKS, 1972, p. 86). O fornecedor deveria ir além do zelo pela missão de entregar um produto ou serviço, no caso, deveria ter como objetivo "encantar o consumidor" na atuação do mercado, no sentido de se dedicar a cada particularidade da relação, desde um bom atendimento, com escuta ativa, até um aperfeiçoamento do produto ou serviço oferecido. Sobre o tema, importa destacar que o "consumidor que é bem atendido não precisa ser defendido.” (DESSAUNE, 2017, p. 99).

Nesse contexto, concluiu-se pela necessidade de um equilíbrio entre consumidor e fornecedor na relação contratual, por meio de uma proteção ao consumidor estabelecida pelo Estado, em busca da "igualdade real". A igualdade seria no sentido de tratar desigualmente os desiguais na medida em que se desigualam, pois o que realmente importa é a concretização da 
igualdade formal, a fim de atingir a proteção da parte mais frágil da relação: o consumidor. (BARBOSA, 1999; BULOS, 2018).

Assim, em 1990, consolidou-se no ordenamento brasileiro o Código de Defesa e Proteção do Consumidor, Lei $\mathrm{n}^{0}$ 8.078/90, estabelecido após mandamento constitucional previsto no artigo 48 do Ato das Disposições Constitucionais Transitórias. O direito do consumidor não é apenas um direito fundamental, mas também um princípio da atividade econômica amparado por ordem constitucional, mais precisamente pelo artigo 170, inciso V, da Constituição Federal de 1988. Sobre o assunto, destaque-se que o Estado possui o dever de assegurar a defesa e a tutela de interesses dos consumidores, a partir de uma atuação positiva, como forma de materializar uma extensão do direito fundamental que consiste no acesso aos valores sociais e econômicos. (MARQUES, 2012).

O Direito do Consumidor promoveu um melhor desenvolvimento no mercado, trazendo transparência nas relações do comércio, definindo direitos e, principalmente, deveres do contrato, influenciando diretamente na livre concorrência, e impedindo, em grande escala, infrações rotineiramente utilizadas ( $v . g$. venda casada), promovendo maior eficiência do mercado em favor do consumidor. Destaque-se que o "direito do consumidor define uma nova distribuição dos riscos da oferta de produtos e serviços no mercado.” (MIRAGEM, 2018, p. 39).

Portanto, constata-se que o Código de Defesa do Consumidor (CDC) é um instrumento legal para a aplicabilidade dos princípios constitucionais nas relações de consumo, bem como objetiva promover a proteção dos consumidores. Todavia, em razão da vulnerabilidade existente, é preciso detalhar as características inerentes aos direitos consumeristas, bem como evidenciar e conceituar novos danos.

\subsection{Características dos direitos do consumidor}

No que se refere às características do dos direitos consumeristas, é indispensável identificar os elementos da relação de consumo para que, assim, possam ser aplicados os preceitos do Código de Defesa do Consumidor. A relação jurídica de maneira genérica é formada por quatro elementos: sujeito ativo, sujeito passivo, vínculo jurídico e objeto. (SECCO, 2009; MIRAGEM, 2013). No caso da relação consumerista, observa-se todos os elementos, quais sejam, o consumidor, o fornecedor, as diretrizes do Código de Defesa do consumidor e o produto ou serviço. 
Por força do art. $2^{\circ}$ do CDC, “consumidor é pessoa física ou jurídica que adquire ou utiliza produto ou serviço como destinatário final”. Já fornecedor possui um conceito bem mais abrangente sendo todo aquele que disponibiliza com habitualidade um produto ou serviço, podendo também ser pessoa física ou jurídica "pública ou privada, nacional ou estrangeira, bem como os entes despersonalizados, que desenvolvem atividade de produção, montagem, criação, construção, transformação, importação, exportação, distribuição ou comercialização de produtos ou prestação de serviços", como é possível perceber pela leitura do art. $3^{\circ}$ do referido diploma.

Em função do caráter principiológico, o CDC padroniza um conteúdo multidisciplinar, em um microssistema com destinatários específicos e interesse amplo, no sentido de aplicar normas de direitos de solidariedade. O propósito da lei consumerista é implantar uma política nacional do consumo com fins de proporcionar dignidade, saúde, segurança, proteção de seus interesses econômicos, transparência e harmonia das relações de consumo. "A defesa do consumidor é, indubitavelmente, um tipo de princípio programa, tendo por objeto uma ampla política pública (public policy). A expressão política nacional designa um programa de ação de interesse público". (COMPARATO, 2011, p.66).

O consumo é inerente à sobrevivência do ser humano em sociedade e se apresenta como uma tutela de proteção da pessoa humana em um mercado econômico e lucrativo. (MIRAGEM, 2018). Logo, observa-se que os consumidores e fornecedores são os protagonistas na relação de consumo, possuindo a lei consumerista o preceito maior de harmonizar interesses. Desse modo, a lei deve proteger a parte mais frágil: o consumidor. Este não detém o conhecimento do produto ou serviço, não tem familiaridade do mercado de preços, tampouco da produção, ao contrário do fornecedor, que possui ampla compreensão do que ali propõe, razão pela qual o termo vulnerabilidade deve ser compreendido em sentido amplo.

O princípio da vulnerabilidade do consumidor é a razão basilar para as relações de consumo em decorrência da assimetria de informações, desta maneira, zelando perante o desequilíbrio e impedindo-o. A vulnerabilidade do consumidor se presume, não sendo necessária qualquer comprovação perante o fornecedor, constituindo presunção legal absoluta, já que devidamente adotada pelo Código de Defesa do Consumidor e como forma de isonomia prevista no art. $5^{\circ}$, caput, da Constituição Federal de 1988. (MIRAGEM, 2013).

Deste modo, a vulnerabilidade é inerente ao consumidor e pode decorrer de diferentes aspectos. A vulnerabilidade técnica refere-se ao conhecimento do produto ou serviço, o material utilizado, a qualidade desempenhada, o poder de decisão sobre o preço, ou seja, percepção e clareza da cadeia técnica produtiva. Como obrigação, entende-se a simples atenção 
em que a legislação impõe o dever de conhecimento da informação, bem como o cuidado ao consumidor. A vulnerabilidade econômica, sendo evidente na relação de consumo, uma vez que, em regra, o fornecedor possui o poder econômico bem maior. (MIRAGEM, 2013; NUNES, 2017)

Deve-se ainda acrescentar a vulnerabilidade jurídica, fática e informacional. Aquela corresponde à falta de instrução dos consumidores para compreensão de todas as cláusulas impostas em contrato, sem conhecimento dos direitos que lhes são inerentes, bem como dos deveres compulsórios aos fornecedores. (MARQUES, 2012).

Trata-se a vulnerabilidade fática da discrepância econômica pela falta dos mesmos meios. (MIRAGEM, 2013). Esta materialização ocorre na medida em que alguns grupos (crianças, idosos, enfermos) alcançam a denominada hipervulnerabilidade, ultrapassando o simples critério econômico. Na vulnerabilidade informacional, enfatiza-se que o consumidor é exposto a informações por diversos meios de comunicações que vão muito além da capacidade de discernimento entre a informação útil e a desnecessária, ocasionando implicações negativas. Esta deriva da vulnerabilidade fática, mas permanece com autonomia em razão do necessário controle de qualidade na informação proporcionada ao consumidor, principalmente nas propagadas disponibilizadas no mercado.

Em resumo, se não há vulnerabilidade, não há consumidor. Trata-se de equivalência contratual, dispondo que não se objetiva desequilibrar a balança em favor do consumidor, mas de oportunizar ao mesmo a proteção na medida correta para nivelar o negócio. Proteção em excesso possui o efeito diverso e acaba por desamparar aquele que mais precisa, no caso, o consumidor. Cabe ao intérprete da norma o bom entendimento e aplicabilidade, devendo perceber todas as dimensões ali propostas, além do que preconiza o mercado de consumo. (THEODORO JUNIOR, 2017).

Dessa forma, o ordenamento jurídico brasileiro, tanto na Constituição Federal de 1988 quanto no Código de Defesa do Consumidor, reconhece a presunção da vulnerabilidade do consumidor, mas diverge do estado de hipossuficiência.

Ao contrário da vulnerabilidade, a hipossuficiência não é presumível e tampouco é considerada condição na relação de consumo. A hipossuficiência deve ser comprovada, cabendo ao magistrado atribuir de acordo com o trazido nos autos processuais e a discricionariedade da sua função. (MORAES, 2009). A hipossuficiência vai além da ausência de recursos financeiros, sendo um conceito bem mais amplo no campo consumerista, devendo, portanto, ser analisado conforme o caso concreto. Portanto, todo consumidor é vulnerável pela ausência de informações, mas nem todos são hipossuficientes. (TARTUCE, 2016). 
Destaca-se que o Código de Defesa do Consumidor determina atenção especial à boafé, tanto como princípio, previsto no artigo $4^{\circ}$, inciso III, quanto como cláusula geral, estipulada no artigo 51, inciso IV. O mandamento expresso no CDC garante a compatibilização de interesses, permitindo a "a boa conduta, honestidade, lealdade, respeito e também a ordem econômica." (NUNES, 2017, p. 59). Não se verifica aqui a boa-fé subjetiva, já que esta é a falta de compreensão "condição violadora, impeditiva ou modificadora de seu direito", o que não é o caso.

Nesse contexto, o legislador se propôs além de proteger a parte mais frágil da relação, tratou ainda de promover a boa-fé, não olvidando-se de conceder efetividade para a obtenção de resultados concretos. No artigo $4^{\circ}$, inciso VI e art. $6^{\circ}$, inciso $\mathrm{V}$ do CDC resta evidente a efetividade proposta em legislação, sendo que o princípio da efetividade se estende às autoridades, fazendo com que as tomadas de decisões sejam alicerçadas nas normas consumeristas, protegendo de forma eficaz o consumidor (MIRAGEM, 2013). Por fim, resulta, em última análise, do dever de oferecer máxima efetividade ao direito fundamental da defesa do consumidor.

Portanto, percebe-se que o direito do consumidor não finda em simples normas a serem aplicadas, mas em proteção estatal no âmbito legislativo, executivo e, ainda, no Estado-juiz na análise de casos concretos, sempre observando a vulnerabilidade existente, a boa-fé e a efetividade para implantar uma legítima política nacional do consumo.

\subsection{A lesão aos preceitos consumeristas e a responsabilidade civil}

Os mandamentos consumeristas surgiram com o intuito de evitarem práticas abusivas, porém, estas não deixaram de existir. Questiona-se, contudo, o que a ordem jurídica confere às violações aos direitos do consumidor e de que forma resta configurada a responsabilidade civil (DELGADO; GICO JUNIOR, 2019) em decorrência das lesões aos preceitos consumeristas.

A manifestação da atividade humana traz em si a preocupação com a responsabilidade, ou seja, quando há violação aos preceitos do consumidor, independe dele ter sido efetivamente lesado ou não, há um cometimento de um ilícito. A responsabilidade civil é o resultado da imputação civil do dano a pessoa que lhe deu causa ou que responda pela indenização correspondente. (NERY JUNIOR, 2014; NUNES, 2017). Há responsabilidade civil quando ocorre violação de um dever jurídico original ou uma norma cogente, tendo o dever de indenizar a vítima, de forma compensatória ou reparatória (MIRAGEM, 2015; VENOSA, 2018). 
Destaque-se que o Código Civil Brasileiro de 2002 traz disposição sobre responsabilidade objetiva, em conjunto com os artigos 186 e 927, mas também não despreza a responsabilidade subjetiva, aplicando cada uma conforme o caso. Desse modo, da responsabilidade civil é possível extrair quatro elementos: conduta (positiva ou negativa), culpa, dano e o nexo de causalidade; identificando-se a culpa como pressuposto geral da responsabilidade civil (CAVALIERI FILHO, 2014; ROSENVALD, 2017; GONÇALVES, 2018), ou como elemento acidental. (GAGLIANO; PAMPLONA, 2013).

Contudo, a comprovação da culpa do agente causador do dano apenas se faz necessária na responsabilidade subjetiva, uma vez que na responsabilidade objetiva extrai-se, apenas, a conduta, o dano e o nexo causal, sendo irrelevante a ocorrência de culpa, esta é a que prevalece na relação consumerista, conforme preceitua o Código de Defesa do Consumidor, com exceção apenas dos profissionais liberais, nos termos do artigo $14, \S 4^{\circ}$ do mesmo diploma. O preceito consumerista além de tentar evitar o dano, caso este ocorra, tem a finalidade que o ressarcimento seja de forma efetiva e rápida, portanto, para que seja atingido esse fim, necessário se faz afastar o conceito de culpa, evoluindo para o que se visualiza no artigo 12 do CDC.

A conduta, seja ela positiva (ação) ou negativa (omissão), é o primeiro elemento a ser verificado em uma possível responsabilidade, pois toda responsabilidade decorre de uma conduta. (STOCO, 2014). O dano pode ser considerado como elemento essencial, posto que pode haver conduta e até mesmo culpa, mas sem o prejuízo não há que se falar em responsabilidade civil (GONÇALVES, 2018). Todavia, é preciso esclarecer que, para o instituto da responsabilidade civil, o dano é todo prejuízo resultante de uma lesão antijurídica de bem alheio, seja ele econômico ou não-econômico, de natureza individual ou coletiva, resultante de ato ou fato antijurídico que viole qualquer valor inerente à pessoa humana, ou atinja coisa do mundo externo que seja juridicamente tutelada, posto que a particularidade do dano ser oriundo de um ato ou fato antijurídico é que lhe guarnece a condição de lesão. (NORONHA, 2015).

Quanto ao nexo de causalidade, este é o elemento fundamental para a caracterização, pois se constitui no liame entre a conduta e o dano, sendo o grande protagonista da responsabilidade civil, por meio do qual pode-se identificar o ofensor. Salienta-se que quando mais de uma conduta possa ter colaborado com a repercussão danosa, deve ser utilizada a causa predominante, uma vez que esta foi a essencial para a ocorrência do dano.

Há três funções no instituto da responsabilidade civil: reparatória, punitiva e precaucional. A reparatória visa a tentativa de minorar o dano, no sentido de retornar ao status 
quo ante, seja devolvendo a coisa ou, caso impossível, compensando-a com uma indenização em um valor equivalente, com função de transferência dos danos do patrimônio do lesante ao lesado como forma de reequilíbrio patrimonial. (ROSENVALD, 2017).

Já a função punitiva se caracteriza pelo efeito dado a ausência de cautela do fornecedor, uma vez que a mera reparação não é suficiente ao desestímulo da prática ofensora consumerista. Aqui, pode-se ressaltar a Teoria do Desestímulo (Punitive Damages), modalidade aplicada nos Estados Unidos da América, com origem no direito Romano. O modelo Punitive Damages desestimula a reincidência do ofensor, aduzindo que a finalidade da indenização punitiva é evitar que o dano imposto ao consumidor seja lucrativo, devendo ter mais força no poder judiciário brasileiro. (MELO, 2015).

No que toca à função precaucional da responsabilidade civil, refere-se a um efeito de cuidado, transmutando-se em estímulo a observância dos direitos e deveres da relação com fins de evitar uma ofensa. A função pracaucional possui o objetivo de inibir atividades potencialmente danosas, tendo natureza de prevenção de danos, já que desestimula a reiteração de condutas lesivas e incentiva a prática do cuidado.

De uma maneira geral, a função reparatória não seria suficiente para impedir o fornecedor de se precaver de condutas ofensivas, sendo necessária a função punitiva como meio de persuasão, amparada, ainda, pela função precaucional, com caráter socioeducativo e com fins de coibir práticas ofensivas, visando reestabelecer o equilíbrio da relação.

Outrossim, deve-se destacar que tradicionalmente a doutrina e a jurisprudência consideram tutelado o dano material e o moral. Esse costume, a rigor, não é a definição adequada, sendo mais coerente a utilização de dano patrimonial e dano extrapatrimonial. (NORONHA, 2015). O dano patrimonial consiste de uma lesão concreta ao patrimônio, sendo medido pela diferença entre o valor atual do patrimônio da vítima e aquele que teria, no mesmo momento, se não tivesse sofrido a lesão. Não somente atinge o patrimônio existente, mas também impede o crescimento esperado, compreendendo uma perda atual (dano emergente) ou futura (lucro cessantes).

Em paralelo, o dano extrapatrimonial possui uma difícil conceituação, já que lida com circunstâncias imateriais. São danos que não resultam em efeito negativo econômico, mas sim em consequências desagradáveis à vida da vítima. CAVALIERI FILHO, 2014; COELHO, 2014). O ordenamento jurídico brasileiro já tem posicionamento firmado na cumulação do dano patrimonial e dano extrapatrimonial incidente sobre o mesmo fato, alias, Súmula n. 37 do Superior Tribunal de Justiça consolidou e extinguiu qualquer dúvida potencialmente existente. 
Destaca-se, ainda, que mesmo sem previsão legislativa específica, o dano à imagem, o dano estético e o dano à integridade psicofísica passaram a ser entendidos pelos tribunais como lesão ressarcível. Todavia, além dos mencionados, novos danos estão tomando força e sendo reconhecidos tanto em doutrina quanto em jurisprudência, principalmente em decorrência da evolução da responsabilidade civil e da extensão do conhecimento das prerrogativas consumeristas, sendo primordial a análise da tutela protegida e do bem jurídico violado.

\subsection{Dos novos danos: ampliação das hipóteses de dano indenizável}

O reconhecimento do princípio da Dignidade da Pessoa Humana, em conjunto com a evolução da responsabilidade civil, bem como a tutela consumerista voltada à proteção do vulnerável, trouxe a discussão de novas espécies de danos. A finalidade é assegurar maior amparo para as vítimas das barreiras criadas por fornecedores, tendo como notórias espécies de novos danos: a perda de uma chance, abandono sócio afetivo, dano morte, dano punitivo, dentro outros.

O conceito de dano progrediu, tratando-se de atenuação de um bem jurídico, seja de qualquer natureza, como a honra, a liberdade, a chance, o tempo. O significado do dano está na lesão ao interesse daquele que usufrui o bem, não se limitando na simples alteração do bem. (CARNELUTTI, 2015).

O dano será injusto quando afetar elemento primordial da dignidade da pessoa humana, incluindo se resultar de conduta ilícita. Para a autora, admitindo o "dano injusto" acarretar-seia em uma melhoria na constatação do dano, uma vez que a conduta, independente de ser lícita ou não, seria decorrente da violação de princípios e valores previstos na Constituição Federal e na legislação infraconstitucional. (MORAES, 2016).

A dignidade da pessoa humana como o referencial, sendo composta por igualdade, liberdade, integridade psicofísica e a solidariedade, elementos que não podem ser lesados sem uma contraprestação apropriada da responsabilidade civil. As habituais modalidades de dano, moral e material, não são capazes de tutelar a dignidade da pessoa humana em toda a sua heterogeneidade, assim, o reconhecimento de novos danos favorece a efetivação da reparação integral à pessoa humana. (CAPPELARI, 2010).

A responsabilidade civil contemporânea possibilita a proteção do ser humano em face de violação à sua dignidade e a partir do surgimento de novos interesses, principalmente os de natureza existencial, oportunizando a consideração e análise da tutela pretendida pelos tribunais. Sobre o tema, importa destacar que as modalidades de dano não patrimonial (v.g. 
dano à integridade psico-física, dano estético, dano à saúde) estão se aliando a outras e origem mais recente. Para classifica-las, a "doutrina de toda parte tem empregado expressões como novos danos ou novos tipos de danos" (SCHREIBER, 2015, p.92).

A falta de previsão de um interesse específico não impede o reconhecimento como interesse jurídico, cabendo à análise de cada caso concreto, podendo falar-se em criação de jurisprudência. No caso, os interesses que cabem tutela não necessariamente precisam estar expressos no ordenamento, devendo o intérprete aplicar conforme estudos de princípios e normas, os quais a doutrina adaptou-se a chamar de microssistema. Visualiza-se que a falta de um conceito legal de dano, acrescida da não tipificação das tutelas, compele à jurisprudência o papel essencial na identificação dos interesses merecedores de tutela. A tutela aos novos danos se configura necessária em razão da legislação não acompanhar a evolução e a mudança da sociedade, sendo primordial a colaboração do Judiciário.

Anteriormente ao Código de Defesa do Consumidor, a parte mais frágil da relação comercial enfrentava uma barreira praticamente insuperável para provar a culpa do fornecedor, além das lacunas específicas para regulamentar a transação. Posteriormente, o obstáculo foi em efetivar as normas ali disciplinadas, principalmente no que consiste a qualidade dos produtos e serviços ofertados no mercado.

Nessa conjuntura, visualiza-se um grande desafio dos consumidores no que consiste ao tempo empregado em busca da solução para problemas ocasionados por fornecedores, acarretados desde o mau atendimento e, até mesmo, à má prestação dos serviços, vislumbrandose que o desvio produtivo é um novo dano, ainda que seja uma nova espécie de dano extrapatrimonial, sendo, no mínimo, nova hipótese de dano moral propriamente dito, razão pela qual aprofundar-se-á no próximo capítulo na análise do desvio produtivo do consumidor no tempo, como bem jurídico tutelado e nos desdobramentos decorrentes.

\section{O ABUSO DO DIREITO E A TUTELA DO TEMPO}

Após a compreensão dos direitos do consumidor e das características que lhes são inerentes, verificação das lesões cometidas, bem como exposição do conceito de "novos danos", passa-se à abordagem sobre o desvio produtivo do consumidor no tempo e abuso de direito, considerando o tempo como bem jurídico tutelado para, assim, enfrentar o reconhecimento do dano temporal como uma nova espécie. 
A teoria do abuso do direito pretende continuar a tendência trazida com a modernização do direito civil para que sejam acrescentados "elementos éticos, socializantes e axiológicos ao direito privado, com a valorização do indivíduo" (NERY JUNIOR, 2010, p. 63). O abuso está ligado ao excesso, podendo ser entendido como fato de usar de um poder, de uma faculdade, de um direito ou mesmo de uma coisa, além do que razoavelmente o Direito e a sociedade permitem. Tem-se tornado mais difícil permanecer na esfera de seu próprio direito, pois, ainda que dentro dos limites, é possível que acarrete dano a outrem, podendo gerar o encargo de indenizar.

O tempo possui uma perspectiva dinâmica, tendo em vista tratar-se de um fato comum revelado por um valor, constituindo-se em bem passível de tutela jurídica. No ordenamento jurídico já não mais se permite a aplicação do direito de forma compartimentalizada, empregando-se uma perspectiva holística de análise dos bens jurídicos. Os variados ramos do Direito superam os extremos delineadas pela dogmática jurídica, apoiando-se em princípios e técnicas com o objetivo de máxima atuação das normas constitucionais visando soluções de maior efetividade da proteção à pessoa e redução de assimetrias.

Portanto, é preciso refletir se o abuso do tempo é indenizável e compreender a existência de desvio produtivo do consumidor pelo prejuízo do tempo desperdiçado. Com o advento do Código Civil de 2002, o abuso de direito recebeu abordagem específica e delineada, com criação do estado de perigo e a lesão com fins de combater o abuso, sanando qualquer dúvida potencialmente existente, já que trouxe expressamente no art. 187 que "também comete ato ilícito o titular de um direito que, ao exercê-lo, excede manifestamente os limites impostos pelo seu fim econômico ou social, pela boa-fé ou pelos bons costumes.” Nesse mesmo contexto, o legislador soube reconhecer a importância em conceituar e especificar o abuso de direito, ganhando autonomia e sendo destinado a reprimir o exercício antissocial dos direitos subjetivos.

Apesar de não se constituir em tarefa simples conceituar abuso de direito, o Código Civil de 2002 considera como ato ilícito, inserindo-o no título III (atos ilícitos) do capitulo V (Da Invalidade do Negócio Jurídico). Destaque-se que o "abuso de direito é espécie de ato ilícito, que pressupõe a violação de direito alheio mediante conduta intencional que exorbita o regular exercício de direito subjetivo". (NADER, 2018, p. 130).

O abuso retrata um excesso no direito, considerando que todo ato que não seja essencial à finalidade ali pretendida deve ser encarado como abuso. Não se trata de simples inobservância de limites do próprio direito, posto que estar-se-ia somente diante de uma elementar ilegalidade, acrescentando que os abusos se configuram contra os limites sociais e éticos impostos à atividade individual na vida em sociedade. 
O Código Civil de 2002 preconiza os requisitos do abuso de direito, sendo necessário que esteja em exercício de um direito, mas de forma não usual, por não satisfazer a finalidade social, ou a própria boa-fé, causando dano a outrem. Se o dano for resultado de uma conduta que não se evidencia de um direito, não existirá abuso de direito, pois não há como abusar daquilo que não se tem. O agente responsável civilmente há de estar investido da titularidade de um direito subjetivo, ao exercitá-lo, por si ou subordinados. (STOCO, 2014). Há abuso ao direito quando existe um exercício anormal do direito, não se limitando a uma simples ofensa a um dever jurídico.

O abuso ocorre quando se desconsidera a situação jurídica preexistente com o intuito de alcançar fim lesivo a outro. Para o exercício do direito, haverá o titular de praticá-lo dentro da finalidade que econômica e socialmente se lhe reconhece, caso contrário, estar-se-ia agindo de forma abusiva, em razão de uma conduta antissocial ou antieconômica. (THEODORO JUNIOR, 2017).

Nesse cenário, para que configure abuso de direito é preciso que cause dano a outrem. O abuso de direito foi implementado no atual ordenamento jurídico para substituir a clássica teoria da responsabilidade civil pela orientação, segundo a qual prevalece um sentido de solidariedade social, sendo em sua espécie objetiva, tornando-se desnecessária análise do elemento culpa, bastando analisar a circunstancia dentro no contexto no excesso, do dano e do nexo ali existente, finaliza expondo que o agente responde pelo abuso de sua conduta se tal circunstância vier a ser apurada.

Cumpre assinalar que "se o titular do direito excede seus fins sociais, por exemplo, mas não causa dano à terceiro, não terá havido abuso de direito, para fins jurídicos, pois não preencheu os elementos necessários" (NERY JUNIOR, 2010, p. 88). O titular do direito poderá responder por perdas e danos caso proceda além dos limites do direito e ainda cause dano a outrem, não necessariamente interferindo psíquico da vítima. Sem o prejuízo não haveria o que reparar ou compensar, não podendo dizer, sequer, em ato ilícito em sentido estrito.

Diga-se que o abuso de direito pode ser visualizado em diferentes áreas, possuindo um imenso campo de atuação, seja nas relações negociais (direito do consumidor, por exemplo), nas extracontratuais (direito de vizinhança, por exemplo) e, até mesmo, no âmbito processual (litigância de má-fé, por exemplo). No caso, destaca-se o abuso nas relações de consumo. O próprio CDC dispõe sobre o abuso em diversos artigos e incisos, ordenando mandamentos, estabelecendo meios de combate e, ainda, impondo sansões para a prática.

Sobre o tema, é oportuno assinalar alguns destes dispositivos: o art. 6, IV, estabelece como direito do consumidor a proteção contra publicidade enganosa e abusiva, métodos 
comerciais coercitivos ou desleais, bem como contra práticas e cláusulas abusivas ou impostas no fornecimento de produtos e serviços; o art.28 identifica a possibilidade da desconsideração da personalidade jurídica em caso de abuso de direito; o art. 37 proíbe a publicidade enganosa ou abusiva; o art. 39, exibe o rol de práticas abusivas; o art. 51 elenca as cláusulas tidas como abusivas; o art. 60, prevê a imposição de contrapropaganda quando o fornecedor incorrer em publicidade enganosa ou abusiva; e o art. 67, que prevê pena criminal para este fato.

Em casos consumeristas, tem-se observado a violação a boa-fé objetiva na prática comercial abusiva contra o consumidor, podendo até mesmo tornar nulas cláusulas contratuais que ultrapassem os limites considerados razoáveis. Exemplos disso são as concessões de crédito bancário a maior a consumidor que possui salário bem abaixo dos vencimentos, resultando a contratação em superendividamento da parte vulnerável da relação, caracterizada por abuso na concessão de crédito pela instituição financeira.

De todo o contexto, depreende-se que o abuso de direito resta configurado como clausula geral, possibilitando sua aplicação nos momentos em que houver abusividade sendo cometida em desrespeito as prerrogativas legais, sociais e a boa-fé.

Destaca-se que a Constituição da República Federativa do Brasil de 1988 garantiu o direito à vida, à saúde, à educação, ao trabalho e ao lazer, entre outros, os quais reunidos compõem o princípio da dignidade humana, sendo primordial ao desenvolvimento democrático, demonstrando-se razão maior para a tutela de todos os aspectos inerentes à vida humana. Apesar disso, para que aconteça a concretização das garantias constitucionais é indispensável que o ser humano dispense tempo para cuidar da saúde, dedicar-se aos estudos, desenvolver atividade laboral e, ainda, usufruir do ócio, seja com família, amigos ou sozinho, mas desde que ele mesmo possa decidir como ocorrerá o desfrute dessas atividades, sem qualquer interferência.

Nesse sentido é que a perda de tempo surge como um novo dano, amparado pelos atos rotineiramente presentes na contemporaneidade, já que o homem necessita de empenho diário para a organização e planejamento de suas atividades, objetivando ganhar tempo. O tempo, como bem jurídico, é por vezes escasso, irrecuperável e inacumulável. (DESSAUNE, 2017). Não se trata de apossar o tempo, mas de dar eficácia para que não se perca com inutilidades, pois o tempo não volta, assinalando, ainda, que "a vida se precipita nas profundezas e, do mesmo modo em que de nada serve colocar líquido num recipiente sem fundo, nada pode trazer de volta o tempo". (SÊNECA, 2013, p. 34).

Pode-se dizer que a vida ocorre em um período de tempo e sendo esse período é como uma tela em branco onde é pintada com todos os seus detalhes, sendo inestimável o seu valor. 
Acrescenta ainda que o tempo presente é brevíssimo, passando muitas vezes despercebido para alguns, pois está sempre fluindo, deixando de existir antes mesmo de chegar.

A ideia de tempo não se define a simples opinião subjetiva sobre os encadeamentos do cotidiano, pois no campo jurídico o tempo é parâmetro objetivo utilizado para criar e extinguir direitos. O tempo pode ser considerado sob duas perspectivas: dinâmica e estática. Para o autor, aquela traduz-se em um tempo natural, decorrente de uma situação habitual, fato jurídico em sentido estrito ordinário. Já na estática, o tempo é considerado um relevante bem, possuindo valor e, consequentemente, proteção jurídica.

\section{CONCLUSÃO}

Em resposta ao problema de pesquisa, é possível concluir pela possibilidade de responsabilizar o fornecedor pelo desvio produtivo do consumidor, considerando o prejuízo do tempo desperdiçado na busca pela solução de problemas não ocasionados por este, sobretudo, por respeito aos pressupostos jurídicos de proteção previstos pelo Código de Defesa do Consumidor de 1990 e Código Civil de 2002, aplicando-se a norma constitucional pela expressão da dignidade e redução de assimetrias.

O tempo perdido não pode ser parametrizado senão por súmula vinculante ou disposição legal, mas deve ser configurado como abuso de direito, não restando à pesquisa definir um tempo mínimo que configure o abuso, porque trata-se de uma análise sobre o caso concreto.

Com o progresso tecnológico e com a massificação do mercado de consumo, os direitos consumeristas surgiram como princípios e normas a fim de assegurar os direitos e deveres básicos da relação de consumo. Todavia, desrespeito as normas estipuladas passaram a ser reiterados, fazendo com que o consumidor perdesse tempo em busca de solucionar o problema. Com a globalização e a digitalização, percebeu-se que o tempo perdido nas tentativas para resolver o incidente poderia ser indenizável.

Em razão do objeto que se busca tutelar, o princípio da Dignidade da Pessoa Humana, em conjunto com as diretrizes da responsabilidade civil consumerista, trouxe como uma nova espécie de dano com o intuito de amparar as vítimas da relação de consumo. A ordem jurídica confere proteção ao tempo, mesmo sem constar expressamente, tendo em vista o prejuízo ocasionado a rotina e a alteração na vida programada, ou seja, o abuso do tempo.

Para compreender o abuso do tempo na relação consumerista, identificou-se a violação da boa-fé objetiva habitualmente na prática comercial abusiva contra o consumidor. Para tanto, 
verificou-se que a perda de tempo surge como um novo dano, pois o homem necessita de empenho diário para a organização e planejamento de suas atividades, objetivando ganhar tempo.

Nesse contexto, constata-se que as relações de consumo se apoiam na missão implícita do fornecedor, qual seja, conceder recursos produtivos ao consumidor. Esses recursos são caracterizados pelo adequado fornecimento de produtos e serviços propiciando condições de utilizar-se do seu tempo para competências de sua livre escolha. Portanto, não há possibilidade de realizar simultaneamente duas ou mais atividades, sendo o consumidor, de forma carente e vulnerável, obrigado a despender parcela significativa do seu tempo, desviando do seu planejamento, assumindo custos materiais e obrigações operacionais que não são de sua competência.

Assim, vislumbra-se a responsabilidade civil contemporânea na perspectiva do dano injusto em lugar do habitual ato ilícito, já que afeta aspecto fundamental da dignidade humana, sobretudo de natureza existencial, podendo ensejar indenização por dano extrapatrimonial e patrimonial.

Dessa forma, sopesando os bens jurídicos em questão, concluiu-se que é possível responsabilizar objetivamente os fornecedores pelo Desvio Produtivo do Consumidor, com ressalva apenas aos profissionais liberais, desde que ocorra (i) problema de consumo potencial ou efetivamente danoso; (ii) prática abusiva pelo fornecedor esquivar-se de solucionar; (iii) nexo causal entre a pratica abusiva e dano resultante; (iv) o dano extrapatrimonial e, possivelmente, (v) o dano emergente, lucro cessantes e/ou dano coletivo.

Por fim, acentua-se que o tempo é alicerce tácito da vida, a qual é limitada e funda-se das próprias atividades existenciais que nela se desenvolvem. Isto é, tempo vital de importância incalculável, pois trata-se de um bem escasso, não podendo ser cumulável e tampouco recuperável, devendo, desse modo, ser respeitado. Portanto, o tempo útil já é considerado um bem tutelado, economicamente apreciável, sendo um dano do tempo reconhecido pelo instituto da responsabilidade civil, admitindo, dessa maneira, a reparação pecuniária.

\section{REFERÊNCIAS}

AZEVEDO, Fernando Costa de. Uma introdução ao direito brasileiro do consumidor. In: Revista de Direito do Consumidor, São Paulo, 2009, v. 3, n. 3, p. 234-245.

BARBOSA, Rui. Oração aos moços. 5. ed. Rio de Janeiro: Fundação Casa de Ruy Barbosa, 1999. 
BRASIL. Superior Tribunal de Justiça (STJ). Acórdão em recurso especial $n$. REsp $n^{o}$ 1737412 / SE (2017/0067071-8). Relator: Ministra Nancy Andrighi. Julgado em 05.02.2019. DJe 08/02/2019. Disponível em:

$<$ https://ww2.stj.jus.br/processo/pesquisa/?termo $=1.737 .412 \&$ aplicacao=processos.ea\&tipoPe squisa=tipoPesquisaGenerica\&chkordem=DESC\&chkMorto=MORTO>Acesso em: 19 de mar. 2019.

BULOS, Uadi Lammêgo. Curso de Direito Constitucional. 11. ed. São Paulo: Saraiva, 2018.

CAPPELARI, Récio Eduardo. Os novos danos à pessoa: na perspectiva da repersonalização do direito. Rio de Janeiro: GZ Editora, 2010.

CARNELUTTI, Francesco, apud SCHREIBER, Anderson. Novos paradigmas da responsabilidade civil: da erosão dos filtros da reparação à diluição dos danos. 6. ed. São Paulo: Atlas, 2015, p. 108.

CAVALIERI FILHO, Sergio. Programa de Direito do Consumidor. 4. ed. São Paulo: Atlas, 2014.

COELHO, Fábio Ulhoa. Curso de Direito Civil. 7 ed. São Paulo: Saraiva, 2014.

COMPARATO, Fábio Konder. A proteção ao consumidor na Constituição Brasileira de 1988. São Paulo: Revista dos Tribunais, 2011.

DELGADO, Joedson de Souza; GICO JUNIOR, Ivo Teixeira. Transboundary environmental damage: na analysis of civil liability based on environmental international law and the theory of games. In: Revista Quaestio Iuris, v. 12, n. 1, Rio de Janeiro, 2019, p. 230-245.

DESSAUNE, Marcos. Resumo sistematizado e conclusão da Teoria do Desvio Produtivo do Consumidor. In: DESSAUNE, Marcos. Teoria aprofundada do Desvio Produtivo do Consumidor: o prejuízo do tempo desperdiçado e da vida alterada. 2. ed. Vitória, 2017, p. 270-280.

GAGLIANO, Pablo Stolze. Responsabilidade Civil Pela Perda do Tempo. Jus Navigandi. Disponível em: <http://jus.com.br/artigos/23925/responsabilidade-civil-pela-perdado-tempo>. Acesso em: 31 out. 2018.

GONÇALVES, Carlos Roberto. Direito Civil Brasileiro. Parte geral - 16. ed. - São Paulo: Saraiva, 2018.

GONÇALVES, Carlos Roberto. Direito Civil Brasileiro. Direito das obrigações - tomo II: parte especial, responsabilidade civil. 15. ed. - São Paulo: Saraiva, 2018.

GUGLINSKI, Vitor Vilela. Síntese Histórica do Direito do Consumidor. Portal Jurídico Investidura. Disponível em: < http://investidura.com.br/biblioteca-juridica/artigos/filosofiado-direito/737-sintese-historica-do-direito-do-consumidor >. Acesso em: 20 mar. 2019.

HICKS, John Richard. Prêmio Nobel de Economia de 1972, apud José Geraldo Filomeno, Direitos do Consumidor. 15. ed. São Paulo: Atlas, 2018. 
MARQUES, Claudia Lima. Introdução ao Direito do Consumidor. In: BENJAMIN, Antônio Herman V.; MARQUES, Claudia Lima; BESSA, Leonardo Roscoe. Manual de Direito do Consumidor. 4. ed. São Paulo: Editora Revista dos Tribunais, 2012.

MELO, Getúlio Costa. A teoria do desestimulo (punitive damages) no âmbito consumerista. Âmbito jurídico, 2015. Disponível em: <

http://www.ambitojuridico.com.br/site/index.php?n_link=revista_artigos_leitura\&artigo_id=1 4327\&revista_caderno=10 > Acesso em: 07 abr. 2019.

MIRAGEM, Bruno Barbosa. Como o Direito do Consumidor contribui para o aperfeiçoamento do mercado. Consultor Jurídico, 2018. Disponível em: < https://www.conjur.com.br/2018-fev-28/garantias-consumo-direito-consumidor-ajudouaperfeicoar-mercado > Acesso em: 07 abr. 2019.

MIRAGEM, Bruno Barbosa. Curso de Direito do Consumidor. 7. ed. São Paulo: RT, 2018.

MIRAGEM, Bruno Barbosa. Direito civil: responsabilidade civil. São Paulo: Saraiva, 2015.

MORAES, Maria Celina Bodin de. Danos à pessoa humana. 2. ed. Rio de Janeiro: Renovar, 2016.

MORAES, Paulo Valério Dal Pai. Código de defesa do consumidor: o princípio da vulnerabilidade no contrato, na publicidade, nas demais práticas comerciais: interpretação sistemática do direito. Porto Alegre: Livraria do Advogado, 2009.

MORAIS, Ezequiel. Brevíssimas considerações sobre o dano existencial. Revista Síntese, v. 12, n. 80, São Paulo, dez. 2012, p. 84-98.

NADER, Paulo. Curso de Direito Civil: Parte Geral. 11. ed. Rio de Janeiro: Forense, 2018.

NERY JUNIOR, Nelson; NERY, Rosa Maria de Andrade. Doutrinas Essenciais Responsabilidade Civil. São Paulo: Revista dos Tribunais, 2010.

NORONHA, Fernando. Os danos à pessoa, corporais (ou biológicos) e anímicos (ou morais em sentido estrito), e suas relações com os danos patrimoniais e extrapatrimoniais. São Paulo: Doutrinas Essenciais de Dano Moral, 2015.

NUNES, Luis Antonio Rizzatto. Curso de Direito do Consumidor. 11. ed. São Paulo: Saraiva, 2017.

PEREIRA, Caio Mário da Silva. Responsabilidade civil. 12. ed. Rio de Janeiro: Forense, 2018.

ROSENVALD, Nelson. As funções da responsabilidade civil: a reparação e a pena civil. 3. ed. São Paulo: Saraiva, 2017.

ROSENVALD, Nelson; FARIAS, Cristiano Chaves de. Novo tratado de responsabilidade civil. 2. ed. São Paulo: Editora Saraiva, 2017. 
SCHMITT, Cristiano Heineck. A “hipervulnerabilidade” do consumidor idoso. 2010. Disponível em <

http://srvapp2s.urisan.tche.br/seer/index.php/direito_e_justica/article/view/668/329. > Acesso 07 abr. 2019.

SCHREIBER, Anderson. Novos paradigmas da responsabilidade civil: da erosão dos filtros da reparação à diluição dos danos. 6. ed. São Paulo: Atlas, 2015.

SECCO, Orlando de Almeida. Introdução ao Estudo do Direito. 11. ed. Rio de Janeiro: Lumen Juris, 2009.

SÊNECA, Lúcio Anneo. Sobre a brevidade da vida. Trad. Lúcia Sá Rebello, Ellen Itanajara Neves Vranas e Gabriel Nocchi Macedo. Porto Alegre: L\&PM, 2013.

STOCO, Rui. Tratado de Responsabilidade Civil: doutrina e jurisprudência. 10. ed. São Paulo: Revista dos Tribunais, 2014.

TARTUCE, Flávio. Manual de Direito Civil. 6. ed. São Paulo: Método, 2016.

THEODORO JUNIOR, Humberto. Direitos do consumidor. 9. ed. Rio de Janeiro: Forense, 2017.

VENOSA, Silvio de Salvo. Direito civil: Parte Geral. 18. ed. São Paulo: Atlas, 2018.

Trabalho recebido em 28 de abril de 2019

Aceito em 21 de maio de 2020 